\title{
Open Source: A Metaphor for E-Learning
}

\author{
Alex Koohang \\ University of Wisconsin - \\ Milwaukee, Milwaukee, USA \\ Koohang@uwm.edu
}

\author{
Keith Harman \\ Northcentral University \\ Prescott, Arizona, USA \\ kharman@ncu.edu
}

\begin{abstract}
This paper explores open source as a metaphor for e-learning. It builds the case that e-learning and open source movement are rooted in the constructivist movement and the constructivist movement is itself rooted in the pragmatism and instrumentalism that pervades John Dewey's theories of understanding as applied to learning. As a result, it is recommended that the use of open source as metaphor for e-learning be further explored in three areas: instructional practices, instructional platforms, and instructional philosophy.
\end{abstract}

Keywords: Open Source, E-Learning, Metaphor, Learning Object, Constructivism

\section{Introduction}

Metaphors have proven to be a highly useful tool in the development of theories in the social sciences (Hartzell, 2004; Kendall \& Kendall, 1993; Levassuer, 2004; Wang, 2004). At a minimum, they provide a convenient means by which to create a taxonomy; the first step towards description, then prediction and finally to understanding (Kerssens-van-Drongelen, 2001; Lewis \& Grimes, 1999; Lynham, 2000).

At a practical level, metaphors become essential elements that comprise the everyday language among specialists (Cook-Sather, 2003). For example the statement, "The computer is down," indicates the functional or operational status of a computer (including its programs or software) as opposed to a spatial relationship or orientation. Those familiar with the jargon share this common understanding (Gozzi, 2000).

However such common understandings are the exception, not the rule. The term information superhighway as a metaphor for the Internet has been substantially replaced by cyberspace as a metaphor (Barta-Smith \& Hathaway, 1999). But are they the same? And will cyberspace be replaced by yet another metaphor when wearable computers move from the realm of the exotic to the realm of mass-produced commodity?

These types of questions are of great practical import for educators. Widespread acceptance of

Material published as part of this journal, either online or in print, is copyrighted by the publisher of Informing Science. Permission to make digital or paper copy of part or all of these works for personal or classroom use is granted without fee provided that the copies are not made or distributed for profit or commercial advantage AND that copies 1) bear this notice in full and 2) give the full citation on the first page. It is permissible to abstract these works so long as credit is given. To copy in all other cases or to republish or to post on a server or to redistribute to lists requires specific permission and payment of a fee. Contact Editor@inform.nu to request redistribution permission. online education (as a format of distance learning) has implications far beyond enrollment patterns. It signals underlying, significant changes in how a substantial number of institutions, educators, and their clientele perceive three key factors that essentially frame how online education is implemented: instructional practices (design and delivery), instructional platforms (educational technologies in the 
broadest sense) and instructional philosophies.

The paradigm shift is exemplified by the term e-learning (often used interchangeably with online education and distance learning). The confluence of web-based technologies; continued advances in digital storage; processing and media; and the ongoing boutique approach to software development are at the heart of e-learning. The confluence produces education and learning that become more ubiquitous and more engaging. What emerges is the proverbial "whole that exceeds the sum of its parts."

An adroit way to begin to comprehend the "whole" would be to use a proven approach in the social sciences: identifying an appropriate metaphor that promotes common understanding about elearning. There is nothing revolutionary about such an effort. At the turn of the $20^{\text {th }}$ Century theorists in educational administration adopted a mass production metaphor for public education and subsequently set in motion instructional practices, platforms, and philosophies that remain firmly entrenched today (Dever \& Barta, 2001) although new paradigms using naturalistic models such as chaos theory and complexity theory are being considered (Evers \& Lakomski, 2001).

So here at the turn of the $21^{\text {st }}$ Century educators are presented with this thing known as e-learning where education is delivered online on a mass customized basis using various electronic media. E-learning is often touted as a means to reduce institutional expenses, increase institutional revenues, or both (Harvey, 2004; Moallem, 2004; Porter, 2003).

In addition, e-learning applications initiatives by higher education institutions are considering the open source software/product where the software/ product is freely available for delivering education online (Coppola \& Neelley, 2004). Siemens (2003) suggests that the benefits of the open source model are increased quality, greater stability, superior performance, and improved functionality. Reduced vendor reliance, reusability, reduced costs, auditability (users validating security), reliability, and rapid fixes to bugs/problems are among other benefits open source model can offer.

Regardless of what is real about e-learning versus what is hype, there is a need to identify a metaphor that may be used to better understand e-learning (Kaplan, 2004; Terrio, 2002; Umbach, 2001). A corollary need is to frame or articulate criteria that may be used to identify a metaphor (Gozzi, 1999; Lipton, 2003). Doing so enables researchers and practitioners an opportunity to explore phenomena such as serendipitous learning that occurs online and the ways in which online learning may be multidimensional in nature as opposed to linear or goal-driven. It provides researchers and practitioners an opportunity to explore models of online learning that emphasize the learner or user as opposed to the content, the technological platform, or issues of intellectual property.

\section{Purpose of the Paper}

The purpose of this paper is to establish a philosophical linkage that enables one to explore open source as a metaphor for e-learning. To accomplish this objective, this paper presents the case that: (1) e-learning and open source movement are rooted in the constructivist movement and (2) the constructivist movement is itself rooted in the pragmatism and instrumentalism that pervades John Dewey's theories of understanding as applied to learning.

This paper is organized in manner consistent with its purpose. Open source; open source and elearning; open source and learning objects; and open source and open standards are defined and discussed followed by discussion of theories and principles. Next, the discussion focuses upon presenting the case - a philosophical linkage which defines the conceptual fit between e-learning and open source. The paper concludes with recommendations for exploring open source as a metaphor for understanding e-learning in three key areas: instructional practices, instructional 
platforms and instructional philosophy. Finally, recommendations for carrying out future research are made.

The philosophical linkage presented in this paper is exploratory. It is (to use vernacular) a conceptual treatment or thought piece. This paper is meant only to generate further exploration regarding the theoretical efficacy of the metaphor and only to suggest potentially beneficial methodological approaches to examine the efficacy of the metaphor.

The comprehensive discussion of any of the key concepts is beyond the scope of this paper. It is hoped that this paper will engender interpretive nuances that will add depth to the breadth of the discussion herein.

\section{What is Open Source?}

Open source refers to software's source code that is freely available to anyone who wishes to extend, modify, and improve the code. Some examples of open source projects are Linux (http://www.linux.org), Apache (http://www.apache.org), Mozilla (http://www.mozilla.org), and OpenOffice (http://www.openoffice.org).

The GNU project (http://www.gnu.org) defines free software as "a matter of the users' freedom to run, copy, distribute, study, change and improve the software." Particularly, attention is given to four freedoms. They are:

- The freedom to run the program, for any purpose (freedom 0 ).

- The freedom to study how the program works, and adapt it to your needs (freedom 1). Access to the source code is a precondition for this.

- The freedom to redistribute copies so you can help your neighbor (freedom 2).

- The freedom to improve the program, and release your improvements to the public, so that the whole community benefits (freedom 3 ). Access to the source code is a precondition for this.

The open source model encompasses a set of principles and values that ensure the integrity of open source software. Open Source Initiative (http://www.opensource.org), a not-for-profit organization has proposed 10 items that are widely accepted by the open source community. These items are:

1. Free redistribution

2. Source code must be included

3. Derived works - allow modifications

4. Integrity of the author's source code

5. No discrimination against persons or groups

6. No discrimination against fields of endeavor

7. Distribution of license

8. License must not be specific to a product

9. License must not restrict other software

10. License must be technology-neutral

\section{Open Source and E-Learning}

E-learning is the delivery of education (all activities relevant to instructing, teaching, and learning) through various electronic media. The electronic medium could be the Internet, intranets, extranets, satellite TV, video/audio tape, and/or CD ROM. 
In the past several years higher education institutions have initiated the creation of enterprise open source applications such as course management systems and electronic portfolios. These elearning applications initiatives are initial steps higher education is taking to move away from proprietary software toward open source. With open source, higher education institutions can easily and freely audit their system. The system becomes open and transparent and reduces the vendor lock-in. The system becomes flexible. There will be ultimate access/control, ownership, and freedom. The open system encourages increased exchange of ideas that advances innovation. Young (2004) states that anyone can use open source software, however; successful implementation of open source model depends on 1) community building, 2) agreeing on a common definition of open source, 3) allocating and securing budget for "free" software, 4) encouraging institutions to switch to open source, and 5) have a positive working relationship with companies.

Open source models, by nature, mandate informal formation of communities of practice in which individuals are bond together with common sense of problems working toward common pursuit of solutions. Communities of Practice are not teams. A community of practice is a group of individuals that are informally bound to collaborate on a shared task. These individuals are peers with a common sense of purpose that are working together to accomplish real tasks. Wenger (1998), describes a community of practice in three dimensions "what it is about - its joint enterprise as understood and continually renegotiated by its members, how it functions - mutual engagement that bind members together into a social entity, and what capability it has produced - the shared repertoire of communal resources (routines, sensibilities, artifacts, vocabulary, styles, etc.) that members have developed over time."

Coppola and Neelley (2004) delineated several benefits of open source software for open learning. They are as follows:

- The software evolves more rapidly and organically.

- Users' needs are rapidly met as the OSS [Open Source Software] model harnesses their collective expertise and contribution.

- New versions are released very often and rely on the community of users and developers to test it, resulting in superior quality software tested on more platforms, and in more environments than most commercial software.

- The development "team" is often largely volunteers, distributed, many in numbers, and diverse. Often, paid members of the development team will manage the project and organize the work of the volunteers.

- Security is enhanced because the code is exposed to the world.

Furthermore, the authors believe that the open source model promotes collaboration and sharing of resources. It creates a community of people that work together to achieve common goals. Specifically, in the open learning environment, Coppola and Neelley (2004) suggest that open source model promotes freedom to choose, increases user access/control, encourages link to a global community, promotes quality, and enhances innovation in teaching and learning.

The e-learning movement toward open source model has been evident in the recent years. There are many open source projects dedicated to e-learning. Below is a list of several selected organizations that are involved in helping professors build their e-learning courses:

- Claroline (http://www.claroline.net)

- .LRN Course Management (http://www.collaboraid.biz/products/dotlrn)

- EduZope (http://www.eduzope.org)

- Moodle (http://moodle.org) 
- Pachyderm (http://www.nmc.org/projects/lo/pachyderm.shtml)

- Sakai (http://www.sakaiproject.org)

- Spaghetti Learning (http://www.spaghettilearning.com)

- A Tutor (http://www.atutor.ca)

\section{Open Source and Learning Objects}

The latest entrant in the e-learning environment is learning objects. Learning objects are small pieces of instruction that are granularized and reused in various instructional contexts. Learning objects are stored in repositories. Through a repository, learning objects are accessed and reused in various instructional contexts.

IEEE (2000) defines a learning object as "any entity, digital or non-digital, which can be used, reused or referenced during technology supported learning."

Wiley (2000) defines a learning object as "any digital resource that can be reused to support learning. This definition includes anything that can be delivered across the network on demand, be it large or small." He further asserted that a balanced granularity gives the learning object increased flexibility for reusability.

Learning Objects have many benefits. These benefits are reduced costs, personalized learning, interoperability, standardization, and customization (Elearnspace, 2004). There are many open source websites that offer free learning objects. Below is a list of selected organizations that are providing free learning objects:

- Apple Learning Interchange (http://ali.apple.com/ali/resources.shtml)

- CAREO (http://careo.netera.ca)

- Distributed Learning Object Repository Network (DLORN) (http://www.downes.ca/cgibin/dlorn/dlorn.cgi)

- Educational Object Economy (http://www.eoe.org )

- Educational Software Components of Tomorrow (ESCOT) (http://www.escot.org)

- Filamentality (http://www.kn.pacbell.com/wired/fil)

- Gateway to Educational Materials (GEM) Project (http://www.thegateway.org)

- MERLOT (http://www.merlot.org/Home.po)

- Open Course (http://opencourse.org)

- OpenCourseWare (MIT) (http://ocw.mit.edu/index.html)

- Universitas 21 Learning Resource Catalogue (LRC) (http://www.edlrc.unsw.edu.au )

- Wisconsin Online Resource Center (http://www.wisc-online.com)

Just recently, the Informing Science Institute (http://www.informingscience.org) has announced that it is developing an open resource learning object repository - ISLO (http://www.islo.org). Creators of learning objects can submit their products to the ISLO repository. The learning objects in the repository are accessed by anyone around the world. The unique aspect of this repository is that it will not only allow peer review of learning objects, but also it will allow the communities of practice to extend, modify, and improve learning objects within the repository.

\section{Open Source and Open Standards}

The basis for open source model is the open distribution of the source code. In other words, anyone can examine, modify, change, and improve the source code. Open standards form the foun- 
dation for product interoperability (Vento, 2004). Interoperability is the ability of the product/software to move around multiple platforms. Interoperability ends the product dependency on a specific platform. It allows a product to operate/function in multiple platforms with different protocols and technologies.

Open standards ensure interoperability that is critical to any distributed e-learning system. The open source community, therefore; must implement open standards in creating open source elearning systems. Outlined below are several models of open standards:

- IEEE LO Metadata (LOM) Learning Technology Standards Committee (LTSC) P1484 (http://ltsc.ieee.org)

- IMS (Instructional Management System) Global Learning Consortium (http://www.imsproject.org)

- Advanced Distributed Learning (ADL) Initiative - Shareable Courseware Object Reference Model (SCORM) (http://www.adlnet.org)

- PROMETEUS: PROmoting Multimedia Access to Education and Training in EUropean Society (http://www.prometeus.org)

\section{Theories and Principles}

\section{Constructivism}

Constructivism is rooted in learning theories and principles advanced by Dewey, Piaget, Vygotsky and Bruner. The term constructivism is defined as constructing new knowledge from prior experience (Newby, Stepich, Lehman, \& Russell, 1996).

There are eight principles in which knowledge construction can be facilitated, "(1) provide multiple representations of reality; (2) represent the natural complexity of the real world; (3) focus on knowledge construction, not reproduction; (4) present authentic tasks - contextualizing rather than abstracting instruction; (5) provide real-world, case-based learning environments, rather than predetermined instructional sequences; (6) foster reflective practice; (7) enable context-and content dependent knowledge construction; and (8) support collaborative construction of knowledge through social negotiation." (Jonassen, 1994, p. 35)

Constructivists believe that humans are active learners. They construct new knowledge based on their prior experiences. In a constructivism environment, learning becomes an active process of constructing knowledge in such a way that the learner builds on prior knowledge and experience to draw meaning and construct new knowledge. The instructor is a facilitator that encourages interaction and helps creates social disclosure.

Honebein (1996) put forward seven goals in designing constructivist learning environments:

1. Provide experience with the knowledge construction process;

2. Provide experience in and appreciation for multiple perspectives;

3. Embed learning in realistic and relevant contexts;

4. Encourage ownership and voice in the learning process;

5. Embed learning in social experience;

6. Encourage the use of multiple modes of representation; and

7. Encourage self-awareness in the knowledge construction process. (p. 11)

In a constructivism environment, knowledge construction takes place in individual contexts and through social disclosure, collaboration, and experience. Learning situations represent the normal 
complexities of the real world. Multiple perspectives and multiple representations that encourage cooperative and collaborative learning are encouraged.

The constructivism learning theory has been praised by researchers as a compatible and appropriate design for e-learning instruction (Bannan-Ritland, Dabbagh, \& Murphy, 2000; Hung, 2001; Hung and Nichani, 2001; Oliver, 1999).

\section{Instrumentalism}

The term instrumentalism refers to an adaptive functional dimension of human thought that enhances the survivability of the individual and the species (McCarthy \& Sears, 2000; Wible, 1984). As applied to learning, instrumentalism refers to controlled inquiry or the directed transformation of an indeterminate situation into one that is so determinate in its constituent distinctions and relations that the elements of the original situation are converted into a unified whole that makes some type of social sense or verification that is internalized by each participant (Hung, 2002).

\section{Pragmatism}

Pragmatism as it is used herein is as Dewey understood it. Dewey's definition of pragmatism is summed up in his concept of the "Reflex Arc Concept" (Bredo, 1998, p. 448). Dewey's pragmatism was grounded in more than a simple model of stimulus and response. He argued that the interpretation of a stimulus and the interpretation of a response are grounded within a larger chronological and social context - the Reflexive Arc. Dewey conceived of a stimulus and response differently than a psychologist. To Dewey, a stimulus was some "transaction demanded by nature" while a response is a "historically based adjustment." (Armitage, 2003, pp. 55-58)

It is this perspective that offers great potential for more fully understanding the open source movement and the advent of e-learning. Open source and e-learning are "transactions demanded by nature" because they are products of naturalistic processes harnessed by human intervention. Additionally, open source and e-learning represent "historically based adjustments" because the human intervention that harnessed those naturalistic processes represents a conscious choice driven by historical factors including technological advances and changing perspectives on democracy, education, and private ownership.

\section{The Case for the Philosophical Linkage}

\section{Constructivism, E-Learning, and Open Source}

Freedom via adaptation to changing circumstances is the thread that runs through constructivism, e-learning and open source. Changing circumstances may involve: (1) a change in the needs or desires of the end user, (2) a change in the circumstances of the end user, or (3) a change in the technology (hardware and software) available to the end user. An end user may be an individual, collection of individuals, or technological system on an individual or collective scale.

Under constructivism, formal learning becomes a process of social disclosure facilitated by or enabled by an instructor. As this process of social disclosure unfolds, there is no assumption that there will be or that there should be either predictability or uniformity in terms of what is popularly referred to as learning outcomes.

Similarly, e-learning holds no assumptions as regards the media that learners will employ. It also holds no assumptions as regards the sequence in which various media are employed. Furthermore, e-learning holds no assumptions regarding the duration that various media are employed. 
Indeed this fluidity or adaptability is characterized by the term New Media. Consequently, elearning holds that no one single medium is THE medium prescribed for e-learning. E-learning also holds that no single set or collection of media constitute THE set or collection of media prescribed for learning. The choice of a medium or a set of media is only limited by: (1) the state of nature, i.e. the availability and efficacy of any given medium or set of media and (2) historical factors germane to the learner, e.g. prior experience, skills, personal preference, or external influences such as employers. Thus learning is obtained via adaptation to circumstances.

Open source likewise holds no assumptions prescribing the use of or the adaptation of code or product. Code or product is assumed to be infinitely adaptable regardless of technology or platform.

Perhaps, proponents of open source argue that private ownership of code or product deters its adaptation and subsequently reduces its utility. In its extreme, open source assumes that code or product is naturalistic as opposed to mechanistic with the subsequent assumption that something that is part of nature is a commonweal as opposed to a private good.

Just as e-learning assumes no boundaries or limits upon knowledge and learning, open source assumes no boundaries or limits as regards ownership and application of code. How knowledge and learning are created, obtained, and applied is essentially a heuristic endeavor, i.e. an endeavor involving active learning. E-learning and open source therefore are based upon key assumptions that comprise what is generally known as constructivism. Figure 1 contains elements of constructivism that are shared between e-learning and open source.

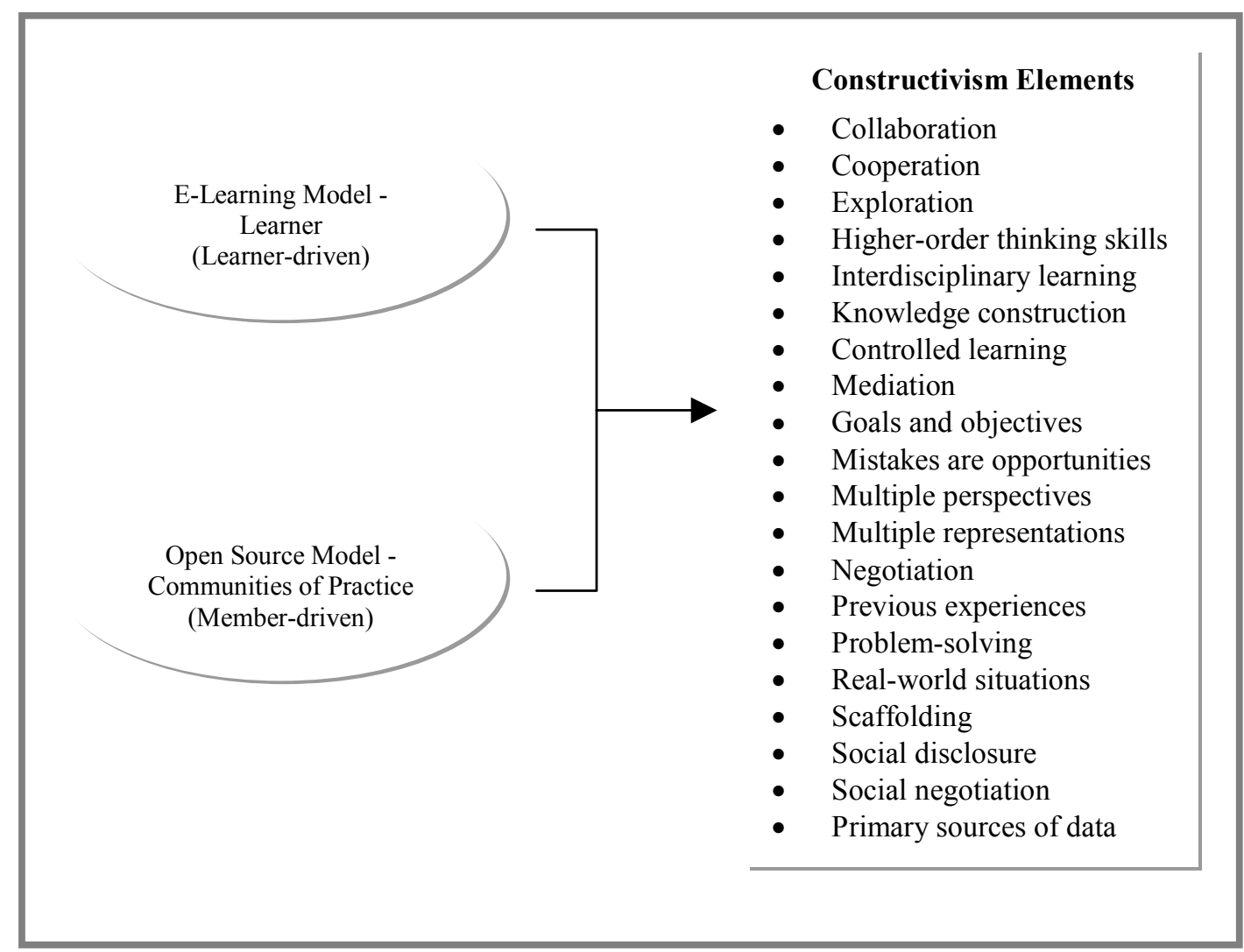

Figure 1: Elements of Constructivism Shared by E-Learning and Open Source 


\section{Constructivism and Dewey's Pragmatism and Instrumentalism}

The freedom to adapt to changing circumstances and to derive meaning from it is a thread that also runs through pragmatism and instrumentalism (as Dewey understood them). Dewey's "Reflex Arc" for example, assumes a series of or a continuum of responses on the part of the learner as opposed to a response per se. Dewey's paradigm strongly inferred adaptation that was developmental or incremental as opposed to random or chaotic. Constructivism likewise implies a developmental or incremental process - the change in meaning is constructed instead of occurring simultaneously or randomly.

These concepts underlie the paradigm of the active learner. It is worth noting that the nomenclature (words like "construct" and terms like "Reflex Arc") have an ambience of architecture or construction and connote that something is being built. According to Dewey and under constructivism, the learner is active - creating and not just responding, indeed one might suggest that at a certain point the boundary between responding and creating becomes essentially indistinguishable.

Given this insight and coupled with the convergence of media that characterizes e-learning, it is plausible to suggest that e-learning is essentially akin to open source. In general, under e-learning the experience for the learner becomes open-ended because the content to be learned eventually takes on a new meaning for each learner who encounters it. Similarly, under open source the code encountered by an end user takes on a new meaning for that end user as that code is adapted to the specific needs and desires of that end user.

Yet the process is not completely private or idiosyncratic. Learning must be placed in context an essentially social process. Code likewise must also be placed in context - it must successfully synergize with other code as well as software and hardware (a socializing process of sorts).

The conceptual fit between e-learning and open source thus indicates that using open source as a metaphor for e-learning is indeed a promising avenue to more fully understand e-learning.

\section{Conclusion}

This paper proposed that open source offers a convenient and potentially beneficial metaphor for e-learning. Firstly, both concepts involve naturalistic processes that are embedded in the same milieu: cyberspace, the digital world, and the human mind. Secondly, both concepts are expressions or manifestations of the same philosophical foundations: constructivism and its underlying foundations as well as pragmatism and instrumentalism as originally articulated by John Dewey. This paper recommends that the use of open source as metaphor for e-learning be more fully explored.

That exploration should focus upon open source as a metaphor for instructional practices - design and delivery, instructional platforms - technologies, and instructional philosophy of e-learning.

The key questions that deserve attention in the area of instructional practices - design and delivery are:

1. Is e-learning essentially a heuristic experience within the context of a shared repertoire of communal resources (routines, sensibilities, artifacts, vocabulary, styles, etc.) that members have developed over time?

2. What does this suggest as regards the design of e-learning?

3. What does this suggest as regards the provision or the delivery of e-learning? 
The key questions that deserve attention in the area of instructional platform - technologies are:

1. Given the open source metaphor is the "commonweal" issue, does e-learning occur in a place, and if so is that place private or public?

2. What if e-learning essentially occurs in the human mind? And if so, is the delivery platform a private or public good?

The key questions that deserve attention in the area of instructional philosophy are:

1. To what extent should e-learning involve automated processes that reduce access to, manipulation of, and capability to absorb knowledge/learning objects?

2. To what extent should e-learning adopt automated processes that increase access to, manipulation of, and capability to absorb knowledge/learning objects?

In addition to the key questions posed for researchers, the open source metaphor assumes transparency of knowledge/learning objects, processes, technology and participants. Likewise, elearning assumes a transparency of knowledge/learning objects, processes, technologies and participants. Are those transparencies analogous? Should they be? Those are questions that require attention from a social, historical, and philosophical perspective.

This paper has presented only a few of the potentially beneficial questions raised by the use of open source as a metaphor for e-learning. The metaphor has great promise and in addition to the questions there remains the work of constructing comprehensive or tentative working models including clearly defined and delineated components and synergies.

As model development moves from a "schemata" or Meta level of analysis to identification and measurement of constructs, the questions posed in this paper will be honed and methodological strategies will subsequently emerge. The journey towards robust, empirical, and analytical dialectic shall thus begin.

\section{References}

Armitage, K. (2003). The continuity of nature and experience: John Dewey's pragmatic environmentalism. Capitalism, Nature, Socialism, 14 (3), 49-72.

Bannan-Ritland, B., Dabbagh, N. \& Murphy, K. (2000). Learning object systems as constructivist learning environments: Related assumptions, theories, and applications. In D. A. Wiley (Ed.), The Instructional Use of Learning Objects: Online Version. Retrieved October 27, 2004, from $\mathrm{http} / / /$ reusability.org/read/chapters/bannan-ritland.doc

Barta-Smith, N. \& Hathaway, J. (1999). Cyberspaces into cyberplaces. Journal of Geography, 99 (6), 253265.

Bredo, E. (1998). Evolution, psychology, and John Dewey's critique of the "reflex arc concept." The Elementary School Journal, 98 (5), 447-466.

Cook-Sather, A. (2003). Movements of mind: the "Matrix," metaphors and re-imagining education. Teachers College Record, 105 (6), 946-977.

Coppola, C. \& Neelley, E. (2004). Open source open learning: Why open source makes sense for education. Retrieved October 27, 2004, from http://www.rsmart.com/assets/OpenSourceOpensLearningJuly2004.pdf

Dever, M. \& Barta, J. (2001). Standardized entrance assessment in kindergarten: A qualitative analysis of the experiences of administrators, teachers, and parents. Journal of Research in Childhood Education, $15(2), 220-233$.

Elearnspace. (2003). Why We Should Share Learning Resources. Retrieved October 27, 2004, from http://www.elearnspace.org/Articles/why we should share.htm 
Evers, C. \& Lakomski, G. (2001). Theory in educational administration: naturalistic directions. Journal of Educational Administration, 39 (6), 499-520.

Gozzi, J. (1999). The power of metaphor in the age of electronic media. Etc., 56 (4), 380-404.

Gozzi, J. (2000). Zombie computers. Etc., 57 (3), 349-352.

Hartzell, G. (2004). The metaphor is the message. School Library Journal, 48 (6), 33.

Harvey, A. (2004). Building a learning library. The British Journal of Administrative Management, (3/4), 26-27.

Honebein, P. (1996). Seven goals for the design of Constructivist learning environments. In B. Wilson, Constructivist learning environments, (pp. 11-24). New Jersey: Educational Technology Publications.

Hung, D. \& Nichani, M. (2001). Constructivism and e-learning: balancing between the individual and social levels of cognition, Educational Technology, 41 (2), 40-44.

Hung, D. (2001). Design principles for web-based learning; implications for Vygotskian thought. Educational Technology, 41 (3), 33-41.

Hung, D. (2002). Metaphorical ideas as mediating artifacts for the social construction of knowledge: implications from the writings of Dewey and Vygotsky. International Journal of Instructional Media, 29 (2), 197-214.

IEEE (2000) Draft Standard for Learning Object Metadata Version 6.1. Retrieved October 27, 2004, from http://ltsc.ieee.org/wg12/

Jonassen, D. (1994). Thinking technology. Educational Technology, 34 (4), 34-37.

Kaplan, S. (2004). Let me hear your web sights: Visual and aural metaphors for the Internet. Idaho Law Review, 40 (4), 299-313.

Kendall, J. \& Kendall, K. (1993). Metaphors and methodologies: Living beyond the systems machine. MIS Quarterly, 17, (2), 149-171.

Kerssens-van-Drongelen, I. (2001). The iterative theory-building process: Rationale, principles and evaluation. Management Decision, 39 (7), 503-512.

Levassuer, R. (2004). Open system theory and organizations. Futurics, 28 (3/4), 82-88.

Lewis, M. \& Grimes, A. (1999). Metatriangulation: Building theory from multiple paradigms. The Academy of Management Review, 24 (4), 672-690.

Lipton, J. (2003). Mixed metaphors in cyberspace: Property in information and information systems. Loyola University Chicago Law Journal, 35 (1), 235-274.

Lynham, S. (2000). Theory building in the human resource development profession. Human Resource Development Quarterly, 11 (2), 159-178.

McCarthy, C. \& Sears, E. (2000). Deweyan pragmatism and the quest for true belief. Educational Theory, $50(2), 213-227$.

Moallem, M. (2004). Distance learning and university effectiveness. [Review of Caroline Howard, et al. Distance learning and University Effectiveness: Changing Educational Paradigms for Online Learning. Information Science Publishing. 1-5940-178-X (h/c) 1-59140- 221-2 (s/c) 1-59140-179-8 e-book, 2004)] Information Management, 17 (3/4), 29-30.

Newby, T., Stepich, D., Lehman, J., \& Russell, J. (1996). Instructional technology for teaching and learning: Designing instruction, integrating computers, and using media. NJ: Prentice Hall.

Oliver, R. (1999). Exploring strategies for online teaching and learning. Distance Education, 20 (2), 240254.

Porter, L. (2003). ABCs of e-learning: Reaping the benefits and avoiding the pitfalls. Research Library, 50 (2), 273. 
Siemens G. (2003). Open source content in education: Part 2 - Developing, sharing, expanding resources. Retrieved October 27, 2004, from http://www.elearnspace.org/Articles/open_source_part_2.htm

Terrio, R. (2002). Electronic metaphors and paper realities. Progressive Librarian 21 (Wint), 28-37.

Umbach, J. (2001). Metaphors as web jargon. Feliciter, 47 (3), 120.

Vento, C. (2004). Open system and open source LMS: Settling the debate for the benefit of higher education. E-Learning Dialogue. Retrieved October 27, 2004, from http://www.campustechnology.com/news_article.asp?id=9267\&typeid $=155$

Wang, T. (2004). From general system theory to total quality management. Journal of Academy of Business $4(1 / 2), 394-400$.

Wenger, E. (1998). Communities of Practice: Learning as a Social System. Retrieved October 27, 2004, from http://www.co-i-l.com/coil/knowledge-garden/cop/lss.shtml

Wible, J. (1984). The instrumentalisms of Dewey and Friedman. Journal of Economic Issues, 18 (4), 10491070.

Wiley, D. A. (2000). Connecting learning objects to instructional design theory: A definition, a metaphor, and a taxonomy. In D. A. Wiley (Ed.), The Instructional Use of Learning Objects. Retrieved October 27, 2004, from http://www.reusability.org/read/chapters/wiley.doc

Young J. (September, 2004). Five challenges for open source. Chronicle of Higher Education.

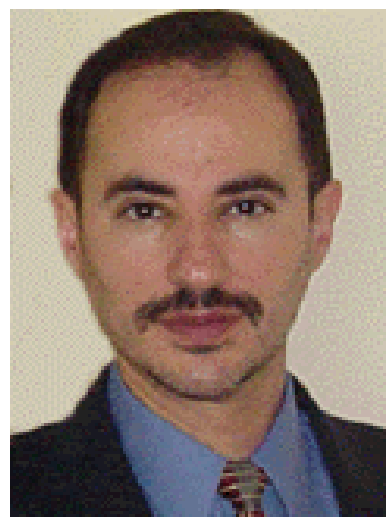

\section{Biography}

Alex Koohang, Ph.D. is Director of Undergraduate Programs, School of Information Studies, University of Wisconsin at Milwaukee. His 20 years of experience in higher education include stints as a faculty member, program director, curriculum product manager, visiting professor, and division director. He has authored or co-authored many papers. Dr. Koohang's current research interest includes e-learning, learning objects, and usability.

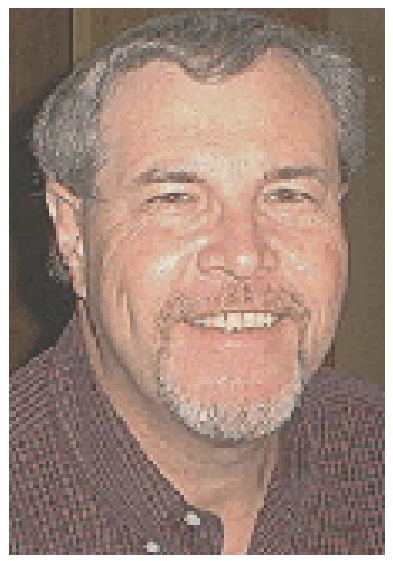

Keith Harman, Ph.D. is Chair of the Department of Business \& Technology at Northcentral University. His 25 years of experience in academe include stints as a faculty member, department chairperson, dean, and academic research administrator. In addition to three books on information management and strategic planning and over two dozen publications and presentations in journals and proceedings, he has served as a guest lecturer and consultant for Fortune 1000 corporations, major universities, private foundations and government agencies. Dr. Harman is currently Associate Editor of the Interdisciplinary Journal of Knowledge and Learning Objects. 